\title{
Ephippia of Cladocera (Crustacea: Branchiopoda) from the Oligocene Tremembé palaeolake, Brazil
}

\author{
C.T. Bergue ${ }^{a *}$, A.A. Kotov ${ }^{b, c, d}$ and M.S.A.S. Maranhão ${ }^{d}$ \\ ${ }^{a}$ Instituto Tecnológico de Micropaleontologia, Universidade do Vale do Rio dos Sinos, São \\ Leopoldo, Brazil; ${ }^{b}$ Laboratory for Ecology of Aquatic Communities and Invasions, A.N. \\ Severtsov Institute of Ecology and Evolution, Moscow, Russia; ${ }^{c}$ Kazan Federal University, \\ Kazan, Russia; ${ }^{d}$ Instituto Geológico do Estado de São Paulo, Água Funda, São Paulo, Brazil
}

(Received 12 August 2014; accepted 18 February 2015; first published online 7 April 2015)

\begin{abstract}
Ephippia of Cladocera (Crustacea: Branchiopoda) are found in the Oligocene deposits of Tremembé Formation (Taubaté Basin, Southeast Brazil). Thirty specimens from a short stratigraphic interval of a $115-\mathrm{m}$ section of a core drilled in Taubaté city, São Paulo state, have been studied. Based on the morphology, we assumed that they might belong to two diferent species of Daphnia (Ctenodaphnia) which lived either in the Tremembé palaeolake or in some surrounding temporary waters. Our find represents the oldest record of fossil ephippia in South America and the second record of Daphnia (Ctenodaphnia) in the former Gondwana. A tentative palaeolimnological interpretation is proposed based on the ephippia occurrences, allied to ostracod and lithological data.
\end{abstract}

Keywords: ephippium; palaeolimnology; Cladocera; Tremembé Formation; palaeolakes; Limnocythere

\section{Introduction}

Cladocera (Crustacea: Branchiopoda) is a group of micrustaceans with a predominantly non-marine mode of life. Like many other crustaceans, most fossil cladocerans are preserved as impressions (Smirnov 1971; Kotov 2007). However, there is a peculiarity of their life cycle which reinforced their fossilisation potential: the gamogenetic female of the majority of cladocerans deposits resting eggs into a hard egg case called an ephippium. Although cladocerans have a Paleozoic origin (Frey 1987; Kotov 2013), the oldest fossil ephippia are known from the Jurassic-Cretaceous boundary (Kotov and Taylor 2011).

Fossil ephippia have been recorded from different regions of the world, in both Mesozoic and Cenozoic non-marine deposits (Dickinson and Swain 1967; Richter and Wedmann 2005; Cromer et al. 2006; Kotov and Taylor 2011). But, as noted by Kotov $(2009,2013)$, in many cases precise correspondence between the morphology of an ephippium and its taxonomic position (at the generic or even family level) is hard to resolve. In recent Cladocera, ephippia are produced only by representatives of the order Anomopoda Sars, 1865. Other orders lack ephippia, including Ctenopoda Sars, 1865, extinct Cryptopoda Kotov, 2007 and extinct Proanomopoda Kotov, 2013,

*Corresponding author. E-mail: ctbergue@gmail.com 
which were common in the Mesozoic (Kotov and Korovchinsky 2006; Kotov 2007, 2013).

The majority of fossil Mesozoic and Cenozoic records of Cladocera concern the Palaearctic. In contrast, reports of fossil ephippia in American deposits are scarce. Studying Pliocene-Pleistocene (?) samples from the Humboldt Formation (Nevada, USA), Dickinson and Swain (1967) found two different cladoceran morphotypes: Wilkimsia gondoliformis Dickinson and Swain, and Daphnia? humboldtensis Dickinson and Swain. Unfortunately, the type material of these taxa is not present at the University of Minnesota nor at the National Museum of Natural History (NMNH) in Washington DC, and probably is lost.

The Pleistocene specimens from Bolivia studied by Purper and Pinto (1980), and identified by them as Daphnia? (Ctenodaphnia) aff. D. humboldtensis (Dickinson and Swain), were ephippia clearly demonstrating the D-shape and having two eggs. These diagnostic traits are characteristic of the subgenus Daphnia (Ctenodaphnia) Dybowski and Grochowski. No Paleogene fossil cladocerans were known from the Americas until the present publication.

The aim of this study is to describe the ephippia from Oligocene deposits of Taubaté Basin, Southeast Brazil.

\section{Material and methods}

\section{Study area}

The Taubaté Basin lies in São Paulo State, Southeast Brazil (Figure 1). Its richest fossiliferous layers belong to the Tremembé Formation, which corresponds to lacustrine deposits (Mezzalira 1989). The rocks of the Tremembé Formation are dated as Oligocene and are mostly mudstones, shales, dolomites and muddy sandstones. These rocks have been deposited under different environmental conditions and correspond

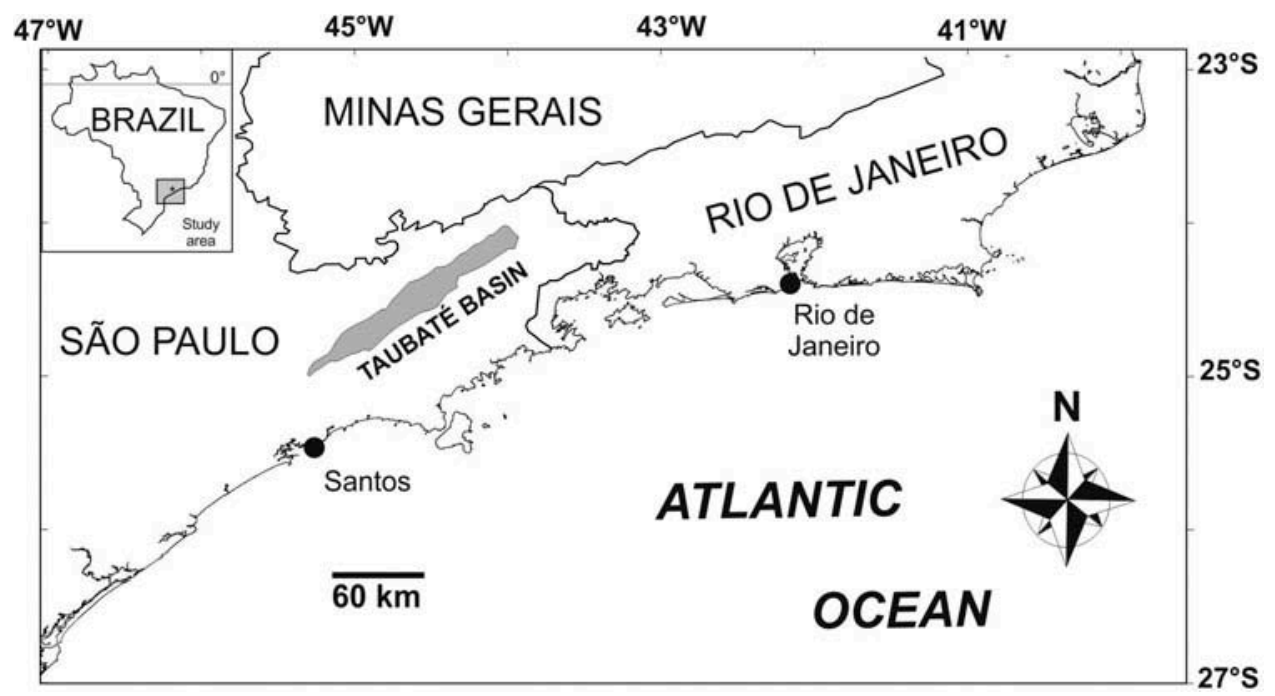

Figure 1. Location of the Taubaté Basin. 
to either shallower or deeper phases of the lake (Riccomini et al. 2004). The material studied originated from a $115-\mathrm{m}$ core drilled in the campus of Universidade de Taubaté $\left(23.01^{\circ} \mathrm{S} / 45.05^{\circ} \mathrm{W}\right)$.

Fourteen samples were taken, mostly from the basal portion. The section is composed of a sequence of shales, argilites and muddy sandstones at the base, followed by thicker layers of sandstones and short intervals of argilites towards the upper part (Figure 2). The samples were prepared according to the methodology for calcareous microfossils, involving soaking in hydrogen peroxide, washing under tap water through meshes and drying in an oven. The final residue was examined under a stereomicroscope, and the specimens picked out and mounted on micropalaeontological cardboard slides for study. Images were taken, and energy-dispersive X-ray spectroscopy (EDS) analysis was carried out, in an EVO MA 15 scanning electron microscope. The specimens figured in this work are held in the Museu de História Geológica do Rio Grande do Sul, at Universidade do Vale do Rio dos Sinos (São Leopoldo, Rio Grande do Sul State, Brazil), under the curatorial numbers ULVG 11529-11534.

\section{Results}

The ephippia recorded in the present work range from 0.7 to $1.18 \mathrm{~mm}$ in length and were obtained from two samples $(73.2$ and $73 \mathrm{~m})$. Most ephippia, apparently, were preserved with their ventral portion slightly open (Figure 3F), but a few were preserved totally closed, either filled (Figure 3G-H) or hollow (Figure 3K). Specimens sectioned with a steel blade revealed, in variable degrees, the hollow space of the respective eggs (Figures 3F-H). In one specimen (Figures 3I-J), interesting details of the ephippium cuticle structure are revealed. The EDS analysis indicates high concentrations of calcium, carbon, oxygen and magnesium and, therefore, a dolomitic composition of the ephippia (Figure 4).

The ephippia most probably belong to a 'recent' taxon - the subgenus Daphnia (Ctenodaphnia) Dybowski and Grochowski 1895. The size of the ephippia is around $1 \mathrm{~mm}$, meaning the size of ephippial females was around $2 \mathrm{~mm}$, which is also characteristic for some species of recent Daphnia (Ctenodaphnia; Mergeay et al. 2005; Kotov 2013). All ephippia (Figure 3A-C, I, J) are elongated, without caudal needle, ventral margin convex, whole surface covered with small papillae, less expressed in region of egg loculi, except dorsal plate, that lacks any sculpture, and two eggs with axes almost parallel to the dorsal margin. The latter trait is diagnostic for Daphnia (Ctenodaphnia; Kotov and Taylor 2011). Papillae are external walls of air chambers, lying between the external and internal cuticle layers of the ephippium (Figure 3J), as known for recent Daphnia. We were able to distinguish two different morphotypes: (1) ephippia with almost equally convex ventral and dorsal margin, slightly narrowing posterior portion, rounded anterior portion, and less expressed sculpture (Figure 3A-B) and (2) ephippia with almost straight dorsal margin, clearly narrowing posterior portion, convex ventral margin, abrupt anterior margin and better developed sculpture (Figure 3I-J).

\section{Discussion}

The ephippia in the Tremembé Formation possibly belong to two different species of Daphnia (Ctenodaphnia). The number of findings of fossil ephippia increases in 


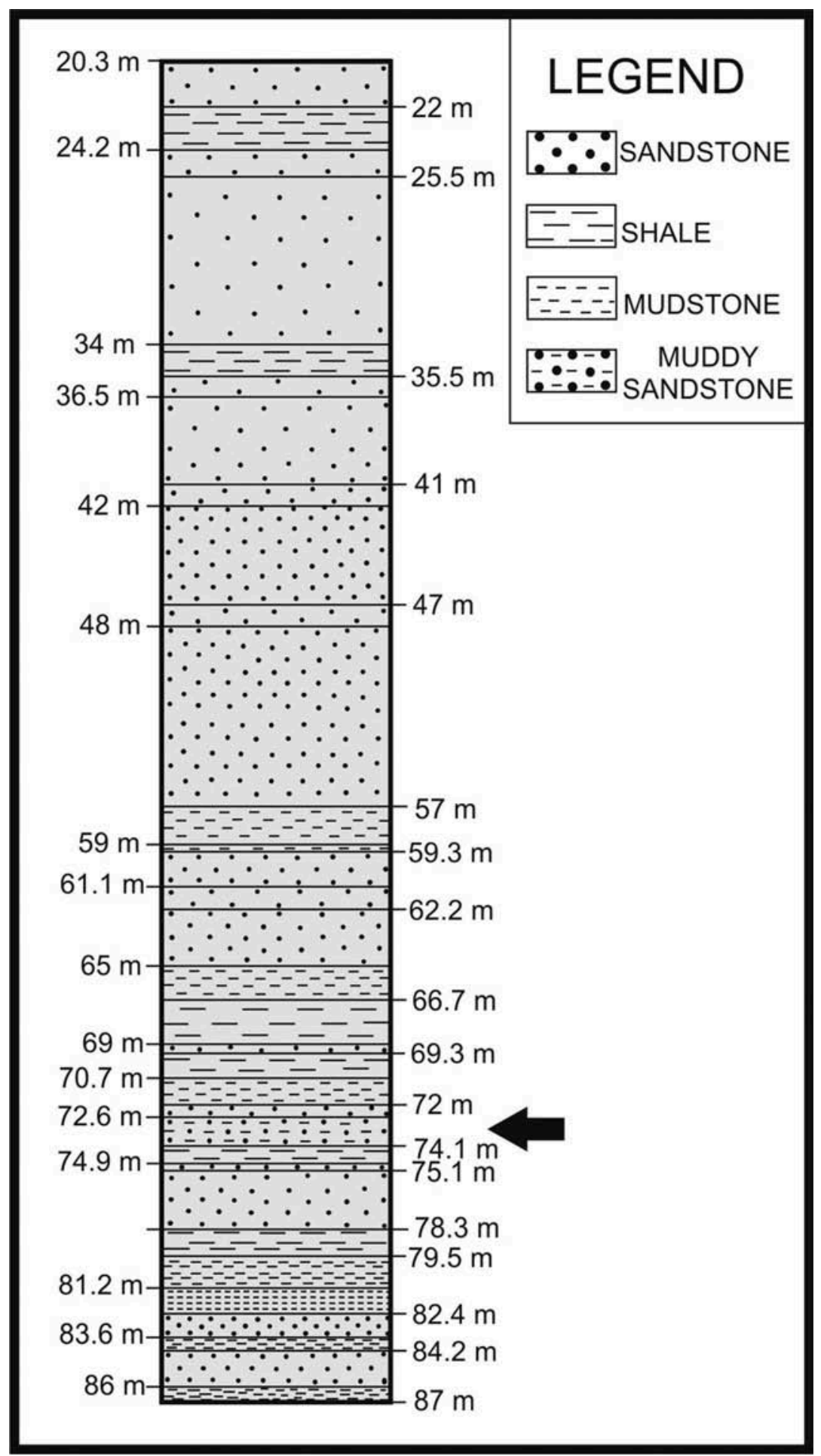

Figure 2. Lithologic profile of the studied core. The arrow indicates the levels where ephippia were found. 

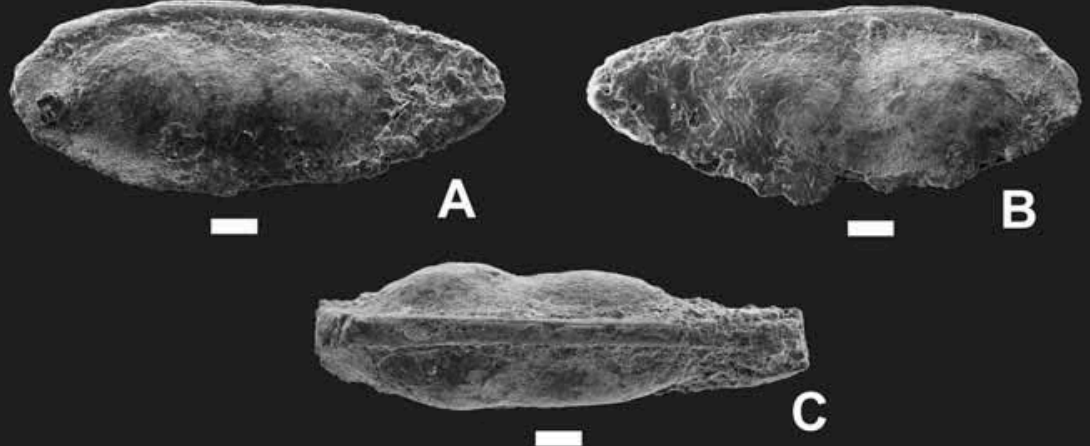

C
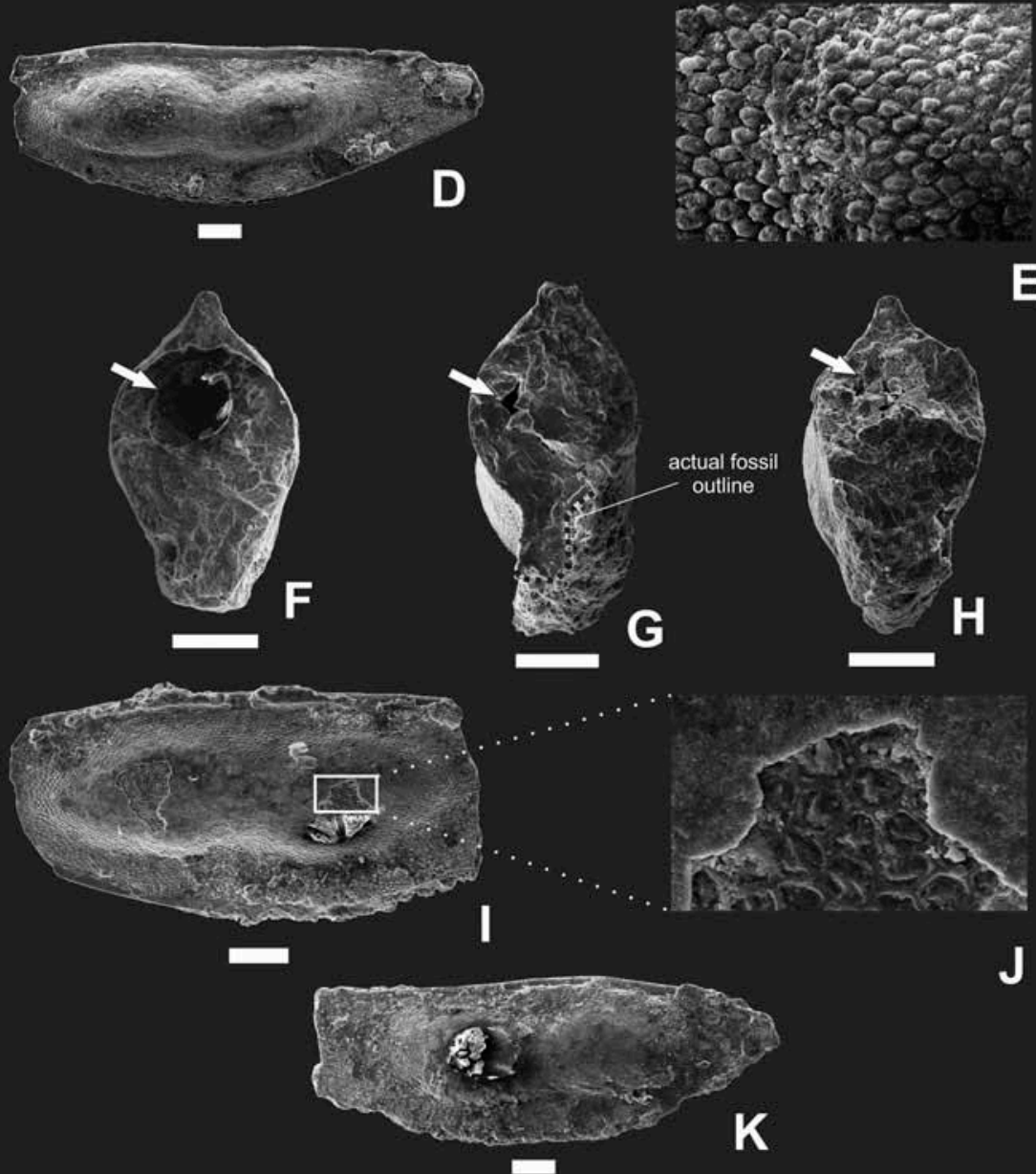

E

Figure 3. Scanning electron microscope images of some ephippia from Tremembé Formation. A-C, ULVG 11529. (A) Right lateral view; (B) left lateral view; (C) dorsal view. D-E, ULVG 11533. (D) Right lateral view; (E) detail of the ephippium surface. $\mathrm{F}-\mathrm{H}$, cross section of ephippia showing the egg place (white arrows). (F and H) ULVG 11531; (G) ULVG 11532. (I) ULVG 11534 lateral view. (J) Detail of the cuticle structure of the same specimen. (K) ULVG 11530. Ephippium with hollow egg chamber. Scale bars $=100 \mu \mathrm{m}$. 

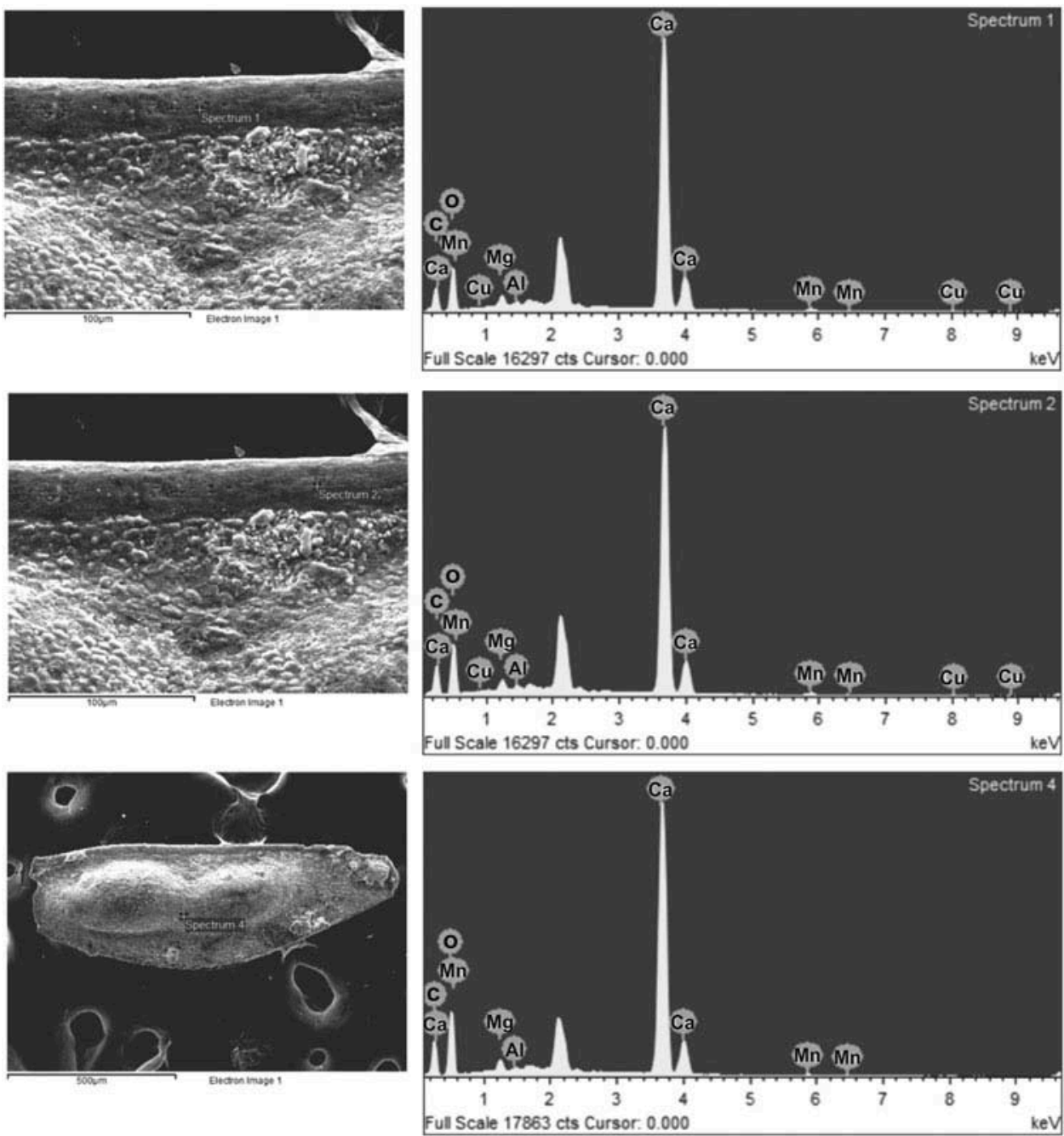

Figure 4. Energy-dispersive X-ray spectroscopy (EDS) analysis carried out in three regions of the ephippium ULVG 11533.

concert with the development of palaeolimnology and deserves, therefore, attention by palaeontologists. Unfortunately, special taxa exclusively for fossil specimens have already been proposed based on very dubious differences from recent taxa (Dickinson and Swain 1967; Lai and Li 1987). But good keys for recent taxa are themselves absent. An approach embracing exclusively fossil taxa could lead to a vicious circle in palaeoecology (first describing a fossil taxon because it must be different from a recent one, and then discussing differences between fossil and recent faunas). Keeping this in mind, we did not try to give any names to the revealed taxa.

We found that at least two taxa of Daphnia (Ctenodaphnia) were present in South America during the Oligocene. Kotov and Taylor (2011) stated that no fossil representatives of Daphnia (Ctenodaphnia) had been recorded in Gondwana, but they had 
no information about the paper of Purper and Pinto (1980). In the present article, we report on the second record of Daphnia (Ctenodaphnia) in the former Gondwana. To date, our ephippia are the oldest cladocerans known from the whole of South America. Our results do not compromise the conclusion (Kotov and Taylor 2011; Popova and Kotov 2013) of a Pangean (instead of Gondwanian) origin of the subgenus Daphnia (Ctenodaphnia). Their presence later in the Oligocene in South America does not contradict either 'Pangaean' or 'Gondwanian' hypotheses of taxon differentiation.

The cladoceran ephippium represents a morphological and ontogenetic adaptation to environmental seasonality. The presence of ephippia is restricted to a short sample interval, which could be explained by either preservation biases or their restricted temporal occurrence in the Oligocene Tremembé lake.

There are many factors which may influence Cladocera occurrence and abundance, ranging from abiotic ones to changes in food webs (Nevalainen et al. 2012). A lack of information on fossil cladoceran autoecology makes understanding the sedimentary record of these crustaceans even more challenging. In addition, there is no guarantee that the ephippia from Tremembe lake were autochthonous, since they could have been introduced from surrounding temporary waters. However, we have tried to give a tentative ecological interpretation of the cladoceran fossils based on ostracod and lithological data from the same core.

The ostracod Limnocythere is an important and widespread non-marine genus and is considered a depth indicator by some authors (e.g. Mourguiart and Montenegro 2002). However, the variability of ecological characteristics relative to other hydrological parameters precludes a broader palaeolimnological use (Martens 1990; Ramón-Mercau et al. 2014). Nonetheless, some degree of association between ephippia and limnocytherids is seen in the present work. In the sample at $73.2 \mathrm{~m}$ where 14 ephippia were recorded, Limnocythere was not found at all but, at $73 \mathrm{~m}$, specimens of Limnocythere were recorded with 16 ephippia. Throughout the interval 71.5-70 m Limnocythere reached its peak of abundance, but no ephippia were registered there.

According to Riccomini et al. (2004), shales (which were commonest between 87 and $66 \mathrm{~m}$ of the core) indicate sedimentation in deep waters, while mudstones and sandstones indicate shallow sedimentation. The ecologic model based on ephippia, ostracods and lithology suggests a deep-lake palaeoenvironment for the deposits at the base of the core, with an upward shallowing trend. It is assumed that the preservation of ephippia would be favoured in deep waters (even if they were allochthonous), since in the shallow waters specimens are more susceptible to reworking. This model, however, fails to explain the absence of ephippia in the interval 87-73.2 $\mathrm{m}$, and more analyses are necessary to assess whether their absence might be attributed to ecological restraints, taphonomy or both.

\section{Concluding remarks}

Therefore, in this paper we report on the oldest cladocerans known to date in South America, and on the second record of fossil Daphnia (Ctenodaphnia) in the former Gondwana. Occurrence of the cladoceran ephippia in just a short interval of the Tremembé palaeolake core indicates that these fossils have potential significance for palaeolimnological reconstructions and stratigraphy of Cenozoic deposits. The 
ephippia-Limnocythere palaeobathymetric model proposed in this study agrees with the lithological one proposed by Riccomini et al. (2004).

\section{Acknowledgements}

Many thanks to Russell J. Shiel for linguistic corrections.

\section{Disclosure statement}

No potential conflict of interest was reported by the author(s).

\section{Funding}

The authors wish to express their gratitude to Dr. Hélio Nóbile Diniz who supplied the core from 'Projeto Piloto de Recarga Artificial na Bacia do Rio Una, Município de Taubaté, which was supported by Fundação de Amparo a Pesquisa do Estado de São Paulo (FAPESP) grant number 2003/07183-1. The senior author wishes to express appreciation for grant no. 474585/ 3013 of Conselho Nacional de Desenvolvimento Científico e Tecnológico (CNPq). AAK is supported by the Russian Government Program of Competitive Growth of Kazan Federal University.

\section{References}

Cromer L, Gibson JAE, Swadling KM, Hodgson DA. 2006. Evidence for a lacustrine faunal refuge in the Larsemann Hills, east Antarctica, during the Last Glacial Maximum. J Biogeogr. 33:1314-1323.

Dickinson KA, Swain FM. 1967. Late Cenozoic freshwater Ostracoda and Cladocera from northeastern Nevada. J Paleontol. 41:335-350.

Dybowski B, Grochowski M. 1895. Spis systematyczny wioslarek (Cladocera) krajowych. Kosmos. 20:139-165.

Frey DG. 1987. The taxonomy and biogeography of the Cladocera. Hydrobiologia. 145:5-17.

Kotov AA. 2007. Jurassic Cladocera (Crustacea, Branchiopoda) with a description of an extinct Mesozoic order. J Nat Hist. 41:13-37.

Kotov AA. 2009. New finding of Mesozoic ephippia of the Anomopoda (Crustacea: Cladocera). J Nat Hist. 43:523-528.

Kotov AA. 2013. Morphology and phylogeny of the Anomopoda (Crustacea: Cladocera). Moskow: KMK Press; p. 638.

Kotov AA, Korovchinsky NM. 2006. First record of fossil Mesozoic Ctenopoda (Crustacea, Cladocera). Zool J Linn Soc. 146:269-274.

Kotov AA, Taylor DJ. 2011. Mesozoic fossils ( $\&>145$ Mya) suggest the antiquity of the subgenera of Daphnia and their coevolution with chaoborid predators. BMC Evol Biol. 11:129.

Lai XR, Li YP. 1987. Ephippia of Cladocera from Tertiary of China. Acta Palaeontol. Sin. 26:171-180.

Martens K. 1990. Revision of African Limnocythere s.s. Brady, 1867 (Crustacea, Ostracoda), with special reference to the Rift Valley Lakes: morphology, taxonomy, evolution and (paleo-)ecology. Archive für Hydrobiologie. 83:453-524.

Mergeay J, Verschuren D, De Meester L. 2005. Daphnia species diversity in Kenya, and a key to the identification of their ephippia. Hydrobiologia. 542:261-274.

Mezzalira S. 1989. Os fósseis do Estado de São Paulo. São Paulo: IGG, Série Pesquisa; p. 155. 
Mourguiart P, Montenegro ME. 2002. Climate changes in the lake Titicaca area: evidence from ostracode ecology. In: Holmes JA, Chivas AR, editors. The Ostracoda - Applications in Quaternary Research. Geophysical monograph 131. Washington (DC): American Geophisical Union; p. 151-165.

Nevalainen L, Luoto TP, Kultti S, Sarmaja-Korjonen K. 2012. Do subfossil Cladocera and chydorid ephippia disentangle Holocene climate trends? The Holocene. 22:291-299.

Purper I, Pinto ID. 1980. Interglacial ostracodes from Wasa Mayu, Bolivia. Pesquisas. 13:161-184.

Ramón-Mercau J, Plastani MS, Laprida C. 2014. A review of the genus Limnocythere (Podocopida: Limnocytheridae) in the Pampean region (Argentina), with the description of a new species, Limnocythere cusminskyae sp. nov. Nov. Zootaxa. 3821:26-36.

Riccomini C, Sant'Anna LG, Ferrari AL. 2004. Evolução geológica do Rift Continental Sudeste do Brasil. In: Mantesso-Neto V, Bartorelli A, Carneiro CDR, Brito-Neves BB, editors. Geologia do Continente Sul-Americano: evolução da obra de Fernando Flávio Marques de Almeida. São Paulo: Becca; p. 383-405.

Richter G, Wedmann S. 2005. Ecology of the Eocene Lake Messel revealed by analysis of small fish coprolites and sediments from a drilling core. Palaeogeogr Palaeoclimatol Palaeoecol. 223:147-161.

Smirnov NN. 1971. A new species of the genus Archedaphnia (Crustacea, Cladocera) from the Jurassic deposits of Transbaikalia. Paleontol zh. 3:119-121. 